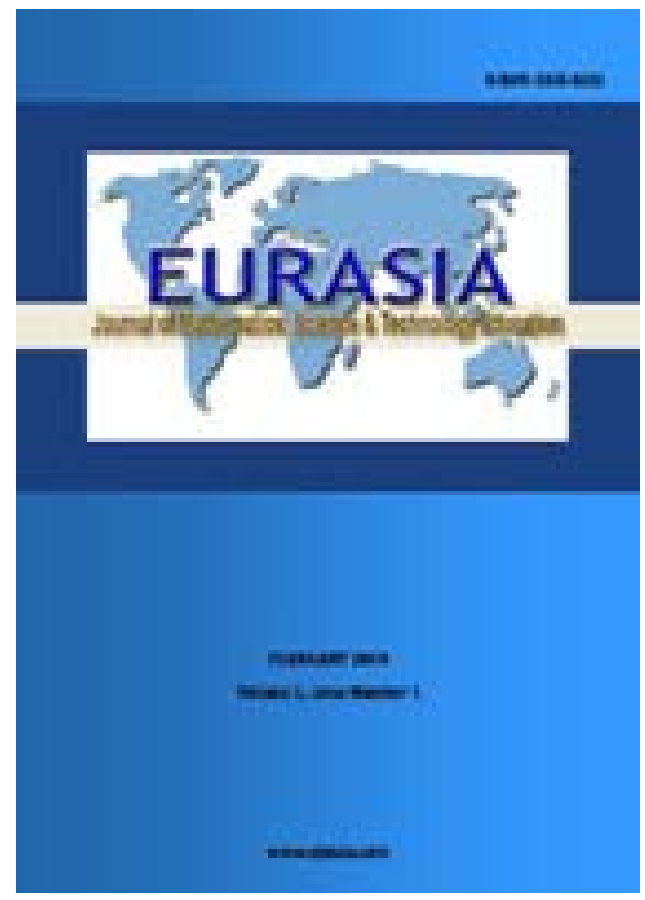

\title{
The Effect of Different Textual Narrations on Students' Explanations at the Submicroscopic Level in Chemistry
}

\author{
Sulaiman M. Al-Balushi \\ Sultan Qaboos University, Sultanate of Oman
}

Received 26 April 2012; accepted 19 December 2012 Published 27 January 2012

APA style referencing for this article: Al-Balushi, S. M. (2013). The Effect of Different Textual Narrations on Students' Explanations at the Submicroscopic Level in Chemistry. Eurasia Journal of Mathematics, Science \& Technology Education, 9(1), 3-10.

Linking to this article: DOI: 10.12973/eurasia.2013.911a

URL: http://dx.doi.org/10.12973/eurasia.2013.911a

Terms and conditions for use: By downloading this article from the EURASIA Journal website you agree that it can be used for the following purposes only: educational, instructional, scholarly research, personal use. You also agree that it cannot be redistributed (including emailing to a list-serve or such large groups), reproduced in any form, or published on a website for free or for a fee.

Disclaimer: Publication of any material submitted by authors to the EURASIA Journal does not necessarily mean that the journal, publisher, editors, any of the editorial board members, or those who serve as reviewers approve, endorse or suggest the content. Publishing decisions are based and given only on scholarly evaluations. Apart from that, decisions and responsibility for adopting or using partly or in whole any of the methods, ideas or the like presented in EURASIA Journal pages solely depend on the readers' own judgment.

(C) 2013 by ESER, Eurasian Society of Educational Research. All Rights Reserved. No part of this publication may be reproduced or transmitted in any form or by any means, electronic or mechanical, including photocopy, recording, or any information storage and retrieval system, without permission from ESER.

ISSN: 1305-8223 (electronic) 1305-8215 (paper)

\section{The article starts with the next page.}




\title{
The Effect of Different Textual Narrations on Students' Explanations at the Submicroscopic Level in Chemistry
}

\author{
Sulaiman M. Al-Balushi \\ Sultan Qaboos University, Sultanate of Oman
}

Received 26 April 2012; accepted 19 December 2012

\begin{abstract}
The effect of different textual versions (macroscopic (control), submicroscopic, and guided imagery) of the explanation of a chemical phenomenon on students' submicroscopic explanation of a related phenomenon was examined. The sample included 152 pre-service science teachers. The three textual versions of the explanation were distributed randomly to the participants. The results revealed that students who received the submicroscopic version and those who received the guided imagery version outperformed students who received the macroscopic version. These results indicated that students' use of the submicroscopic understanding was not spontaneous and they needed to be cued to do so. Also, the submicroscopic mean scores of all three groups were low, and this might be an indication of a weak ability to: 1) translate between macroscopic and submicroscopic levels of chemistry, and 2) transfer a submicroscopic understanding of one phenomenon to another related one.
\end{abstract}

Keywords: chemistry, guided imagery, macroscopic, submicroscopic, textual narration

\section{INTRODUCTION}

Understanding different chemical phenomena requires comprehending their submicroscopic interactions. This stage of comprehension might be described as the "aha" stage for the learners. It is when things start to make sense to them, and then they say "I see!" It also allows learners to visualize and inspect the macroscopic observations by a chemist's eyes and consequently know what a chemist knows (Bucat \& Mocerino, 2009). For successful learning of chemistry to occur, the associations among the macroscopic, submicroscopic and symbolic levels should be mentally constructed (Cheng \& Gilbert, 2009; Gabel, 1993; Johnstone, 1993; Treagust, Chittleborough, \& Mamiala, 2003). Explanations in terms of submicroscopic entities such as atoms, molecules and electrons facilitate

Correspondence to: Sulaiman M. Al-Balushi, Associate Professor of Science Education, Curriculum \& Instruction Department, Sultan Qaboos University

P.O.Box 93, Muscat, 123 SQU, OMAN

E-mail:sbalushi@squ.edu.om students' meaningful understanding and the prediction of macroscopic phenomena. Although macroscopic experience through practical work and experimentation is considered to be a prerequisite for understanding chemical phenomena, for this understanding to be complete it should be finalized through the submicroscopic and symbolic levels (Chandrasegaran, Treagust, \& Mocerino, 2009; Tan, Goh, Chin, \& Treagust, 2009; Treagust \& Chandrasegaran, 2009; Treagust, et al., 2003; Tsaparlis, 2009). To reach this epistemological status of 'meta-visualization', as suggested by Gilbert (2008), students need to: 1) understand the convention for the three different levels, 2) translate between the three levels by thinking back and forth in terms of macro-micro relationships, and 3) be able to construct a representation for a given phenomenon within any of the three levels.

Literatures in chemistry education distinguish between experts and novices. Figure 1 illustrates this distinction. Experts, through years of practice, develop a high spatial ability which allows them to translate easily between the three levels of chemistry. They developed a 


\section{State of the literature}

- Novices think at the macroscopic level most of the time and they could seldom relate one form of representation in one level to related forms in the other levels of chemistry.

- Thinking at the sub-microscopic level of chemistry is perceived as difficult and abstract and, therefore, learning chemistry is believed to be meaningless.

- There is unbalanced emphasis on the three levels of chemistry by teachers and textbooks. Both macroscopic and symbolic levels dominate the textual and pictorial forms of communication in chemistry practice, while the submicroscopic level does not receive the same weight of emphasis.

\section{Contribution of this paper to the literature}

- The current study examines whether students think at and use the submicroscopic level spontaneously in their explanation of chemical phenomena or whether they need to be cued to do so.

- It might be unlikely that students would build up the competence to translate between the levels of chemistry by themselves. Therefore, in order to increase students' submicroscopic thinking, they should be encouraged to translate macroscopic and symbolic representations into submicroscopic ones.

mental competence of "seeing" molecules with their interactions and transformations in their minds (Kozma \& Russell, 2005). They use their understanding of the conventions of each level to make sense of the chemical phenomena and communicate that understanding through representational systems which are used and approved by the chemical community (Davidowitz \& Chittleborough, 2009; Kozma \& Russell, 2005; Treagust, et al., 2003). On the other hand, novices think at the macroscopic level most of the time and they could seldom relate one form of representation in one level to related forms in the other two levels (Kozma \& Russell, 2005; Treagust, et al., 2003). Research on learners of chemistry has shown that being a micromacro thinker is perceived as difficult and abstract and, therefore, learning chemistry is believed to be meaningless (Correia \& Torres, 2007; Tien, Teichert, \& Rickey, 2007; Treagust \& Chandrasegaran, 2009; Van Berkel, Pilot, \& Bulte, 2009). Students struggle when it comes to connecting the three levels of understanding in chemistry (macroscopic, submicroscopic, and symbolic) to produce a comprehensive picture of chemical phenomena (Chandrasegaran, et al., 2009; Davidowitz \& Chittleborough, 2009; Treagust \&
Chandrasegaran, 2009). For instance, students might know how to balance chemical equations correctly. However, they fall short when it comes to producing accurate submicroscopic representations of the same phenomena. Consequently, students might solve mathematical or algorithmic problems while struggling with conceptual problems (Cheng \& Gilbert, 2009; Davidowitz \& Chittleborough, 2009; Halakova \& Proksa, 2007). Treagust and Chandrasegaran (2009) explain that balancing chemical equations becomes a mechanistic approach to students so they do not pay attention to the dynamic interactions involved in the chemical reactions by the submicroscopic species.

Additionally, novices construct their meanings and explanations based on the surface features of chemical phenomena (Kozma \& Russell, 2005). Students sometimes associate physical and macroscopic properties to submicroscopic entities. For instance, they believe that when wood burns its molecules also burn (Treagust \& Chandrasegaran, 2009), there is liquid water between water molecules (Al-Balushi, 2009), the space between gas molecules is filled with air (Nakhleh \& Samarapungavan, 1999), gas molecules are in intrinsic motion as opposed to being pushed externally (Cheng \& Gilbert, 2009), atoms' colors are those of their original substances (e.g. chlorine atoms are green and copper ions are blue) (Treagust \& Chandrasegaran, 2009), and molecules melt when the substance melts (Bucat \& Mocerino, 2009; Van Berkel, et al., 2009). These results show that students have not grasped the conventions of the submicroscopic level. They are still conceptually influenced by the macroscopic conventions due to their prior chemistry knowledge which has been accumulated mostly at the macroscopic level through their everyday experience. They believe that the submicroscopic species in a substance are tiny parts of the continuous substance (Treagust \& Chandrasegaran, 2009) and that they retain its physical properties (Van Berkel, et al., 2009).

In order to reach the submicroscopic level of thinking, students need to understand the 'building blocks' of chemistry, the atoms and molecules (Gabel, 1993; Van Berkel, et al., 2009), and understand the purpose of each level of representation (Treagust, et al., 2003). It would be beneficial for understanding the concept of precipitate formation, for instance, if students are provided with a submicroscopic explanation that "ions attract each other and aggregate together to form larger masses which became visible at the macroscopic level" (Tan, et al., 2009, p. 140). Therefore, the transition from macroscopic to submicroscopic and back to macroscopic becomes obvious. Then, driving an equation as a symbolic representation for such phenomenon from its macroscopic and submicroscopic facets becomes easier. In addition, the abstract nature of chemistry requires the 


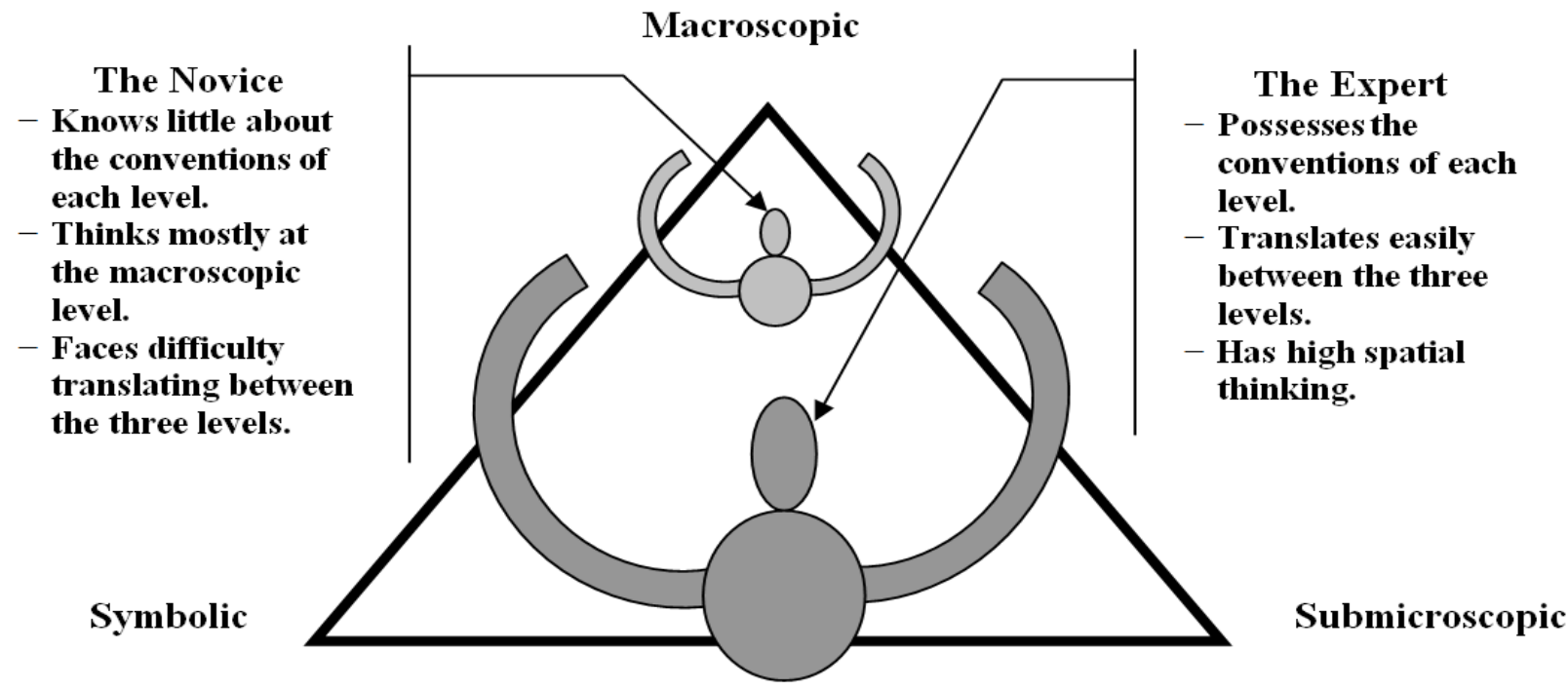

Figure1. Novice vs. Expert comprehension of the three levels of chemistry

using of a variety of symbolic representations such as analogies and models and discussing the relationship of these symbolic representations at the macroscopic and submicroscopic levels. Effective learning of chemistry necessitates the use of symbolic and submicroscopic representations simultaneously in chemical explanations (Treagust et al., 2003).

Although students' conceptualization at the submicroscopic level has received a considerable amount of attention in the literature, there is still a need for exploring related issues such as students' spontaneous use of the submicroscopic level in their explanations and their ability to transfer their submicroscopic understanding of one phenomenon to explain another. These issues are seldom touched upon in the literature. Therefore the current study examines whether students think at and use the submicroscopic level spontaneously in their explanation of chemical phenomena or whether they need to be cued to do so. For this main purpose, the effect of three different textual versions (macroscopic (control), submicroscopic, and guided imagery) of the explanation of a chemical phenomenon on their submicroscopic explanation of a related phenomenon was tested. The guiding research question is:

What is the effect of different textual narrations (macroscopic, submicroscopic and guided imagery) on students' explanations at the submicroscopic level in chemistry?

Submicroscopic and guided imagery textual narrations were written at the submicroscopic level while the third one was written at the macroscopic level and was used as a control. The current study builds on the previous research (Tan et al., 2009; Tsaparlis, 2009) which emphasizes the importance of providing students with the submicroscopic 'building blocks' of chemistry and helping them translate between the macroscopic observations and their related submicroscopic species. The results of this study might help to conclude whether students spontaneously think at the submicroscopic level, as many chemistry teachers would assume they do (Treagust et al., 2003), or whether they need to be cued to do so. This may guide chemistry textbook writers and chemistry teachers when designing their activities and presentations of the subject matter. They might be more able to decide which form of textual narration is more effective in stimulating students' use of submicroscopic conventions in their explanations.

\section{METHODOLOGY}

\section{Design and instrumentation}

An experimental design was used to test the effect of different textual narrations on participants' explanations at the submicroscopic level. The initial phenomenon was the flame formation during the reaction of sodium in water, and the target phenomenon was the sparks formation when two stones strongly hit each other. An instrument of three different versions was designed for this purpose. Each version of the instrument had a different textural narration (macroscopic (control), submicroscopic, or guided imagery) of the explanation of the reaction of sodium in water. Each participant received one version of the instrument. The versions were distributed randomly to the participants. 
Table 1. The three textual versions used in the study

Macroscopic version: when sodium is thrown into water, hydrogen gas is released which reacts with oxygen to form water. This reaction is exothermic. As a result the temperature rises very strongly and flame forms.

Submicroscopic Version: when a piece of sodium is thrown into water, hydrogen gas starts to form. The flame has not yet formed. Each set of two hydrogen atoms bind together by a covalent bond of two electrons orbiting the two atoms. The temperature is high, which makes the hydrogen molecules become disrupted and head rapidly toward the surface. They pour up from the surface and move violently into the air. Some of these molecules collide with oxygen molecules from the air. These collisions disrupt the two hydrogen electrons. They fall into two oxygen empty sub-orbitals. As a result, the two hydrogen atoms bind to one of the oxygen atoms. At the same time, another hydrogen molecule collides with the other oxygen atom and binds to it. The oxygen double bond breaks up and water molecules form. The formation reaction of water molecules is exothermic which makes the formed water molecules spin and vibrate violently and collide with the surrounding molecules which vibrate too. As a result, the electrons of these molecules are thrown into higher atomic and molecular orbitals. As they fall back to their normal locations, photons of light come out. This is the flame you see.

Guided Imagery Version: Imagine that you ride a special vehicle that takes you inside the beaker where the reaction of sodium and water takes place. Your goal is to investigate how the flame forms. You are riding the vehicle now. You are heading towards the sodium piece inside the water. You arrive right after dropping the piece into the water. The flame has not formed yet. Hydrogen gas has started to form. From the window of your vehicle you see hydrogen molecules going upwards. Every two atoms that are bonded together go upward towards the surface. You also see two electrons orbiting the two atoms in order to hold them together. What is the fate of these molecules? You decide to ascend upwards with your vehicle to see what is going on in there.

You feel that the temperature is too high. Molecules are moving very violently. You see that they come out of the surface into the outside air. You decide to monitor one of these molecules. It is heading towards an oxygen molecule. It hits very strongly. Look, the hydrogen electrons, which are orbiting their two nuclei, are disrupted very violently as a result of this collision. Suddenly, they fall into two empty sub-orbitals around one of the oxygen nuclei. Now, the two hydrogen atoms are bonded to that oxygen atom. At the same time, another hydrogen molecule hits the other oxygen atom and binds to it. Suddenly, the double bond that binds the two oxygen atoms breaks up and each atom goes with two hydrogen atoms to form a water molecule. You feel that the temperature rises very rapidly as a result of this molecule formation.

But what do you see?! You see the formed water molecules spin very violently and collide with the surrounding molecules. The movements become unusual in the whole region. Molecules spin and vibrate very violently. As a result, the electrons of these molecules are disrupted greatly and so thrown into higher orbitals. Then they fall back to their normal locations. What's the view? As they fall back to their normal locations, photons of light come out. The process happens several times here and there. Molecules emit photons. The releasing of photons increases. You are now at the middle of the flame. The flame expands. You have to run away. Without any thinking, you start your vehicle and go away from that place.

The three textual narrations are illustrated in table 1. The macroscopic version was used as a control in which the interactions of atoms and molecules were not mentioned and the information included did not go beyond the physical description of the reaction. On the other hand, both submicroscopic and guided imagery versions expressed the submicroscopic explanation of the reaction. The difference between the two forms was that the guided imagery version presented the interactions among atoms and molecules in a narrative story-type format. Guided imagery script is written using a story-like scenario by which the learners are guided to imagine an event or a situation (Al-Balushi, 2009; Berglung, 1997; Galyean, 1983, 1985; Myrick \& Myrick, 1993; Wheatley, Maddox, \& Anthony, 2001).
First, each version of the instrument presents the textual narration. Then it requires the participant to respond to the following question regarding the sparks phenomenon:

Sometimes, sparks form when two stones hit each other strongly. Explain how these sparks form.

The instrument was initially written in English. Four science education professors, one chemistry professor and one psychology professor who had experience with guided imagery research working at a Midwestern university in USA were asked to validate it. Some changes were made based on the comments received from them. Next, it was translated into Arabic, the instruction language in Oman. Then it underwent a translation validation process by four science education professors working at a public university in Oman who 
were fluent in both Arabic and English. Minor changes were made based on the comments received. Finally, the Arabic version was administered to a small pilot group of five college students. A few linguistics changes were made based on this last process.

\section{Participants}

Participants were 152 pre-service science teachers studying at a public university in Oman. The sample included $37(24.3 \%)$ males and $115(75.7 \%)$ females. Forty-two $(27.7 \%)$ of the participants were second year students, $66(43.4 \%)$ were third year students, and 44 $(28.9 \%)$ were fourth year students. According to their major/minors, there were 51 (33.6\%) chemistry/physics students, $44(29.0 \%)$ chemistry/biology students, and 55 $(36.2 \%)$ physics/math students.

\section{Data Collection}

The instrument was administered to participants in their regular classrooms at the university. After a brief introduction, the reaction of sodium in water was shown in a two-minute video clip. Then the three forms of the instrument were distributed randomly. Fifty-one students received the control (macroscopic) version, fifty-one students received the submicroscopic version, and fifty students received the guided imagery version. They were given 15 minutes to complete the instrument.

\section{Data Analysis}

One way Analysis of Variance (ANOVA) was used to compare the three main groups in the experiment: the macroscopic (control), the submicroscopic and the guided imagery. For the purpose of scoring, a six-point rubric scale was designed. Table 2 illustrates this rubric. It was based on the research done on the topic of the submicroscopic nature of matter which appears above in the literature review of this paper. The rubric underwent the same validation process as the instrument which was described above, except for the piloting step. Two raters, the researcher and a science education graduate student, used the rubric to score a sample of twenty students' responses to the question in the instrument. This process resulted in a few changes in the wording of this rubric. The inter-raters reliability was 0.95 .

\section{RESULTS AND DISCUSSIONS}

The dependent variable in this experiment was the overall submicroscopic level in participants' explanations of the sparks phenomenon. The submicroscopic level was measured using the rubric shown in Table 2. The independent variable was the three textual narrations which were distributed randomly to participants. Table 3 illustrates the mean scores and standard deviations of participants' use the submicroscopic level of matter. Table 4 illustrates the ANOVA results for the effect of different textual narrations on participants' use of the submicroscopic level of matter. The results indicated that there were significant differences among the three textual narrations. Then a Tukey HSD pairwise was conducted to determine which pair(s) had significant differences. The results (Table 5) revealed that students who received the submicroscopic version or the guided

Table 2. The rubric used to score participants' use of the submicroscopic level of matter in their explanations of the sparks phenomenon

\begin{tabular}{|c|c|c|c|}
\hline Level & Description & $\begin{array}{l}\text { Misconception(s) } \\
\text { included }\end{array}$ & Score \\
\hline Macroscopic & No submicroscopic term(s) is/are used. & - & 0 \\
\hline \multirow{2}{*}{$\begin{array}{l}\text { Submicro-level I: } \\
\text { Atoms \& Molecules }\end{array}$} & \multirow{2}{*}{$\begin{array}{l}\text { The submicroscopic terms used are limited to atoms and } \\
\text { molecules. }\end{array}$} & Yes & 1 \\
\hline & & No & 2 \\
\hline Submicro-level II: & \multirow{2}{*}{$\begin{array}{l}\text { In addition to atoms and molecules, sub-atomic particles such } \\
\text { as electrons and protons are appropriately integrated in the } \\
\text { response. }\end{array}$} & Yes & 3 \\
\hline Sub-atomic particles & & No & 4 \\
\hline \multirow{2}{*}{\multicolumn{2}{|c|}{$\begin{array}{ll}\text { Submicro-level III: } & \text { In addition to the terms used in submicro-Level II, more } \\
\text { More Sophisticatedsophisticated scientific terms such as ionization energy, atomic } \\
\text { Scientific Terms } & \text { stability, and electronegativity are appropriately integrated in } \\
& \text { the response. }\end{array}$}} & Yes & 5 \\
\hline & & No & 6 \\
\hline
\end{tabular}

Table 3. Means and standard deviations of participants' use the submicroscopic level

\begin{tabular}{lccc}
\hline Textual Narration Type & N & mean & SD \\
\hline Macroscopic (control) & 51 & 0.078 & 0.44 \\
Submicroscopic & 51 & 1.098 & 1.62 \\
Guided Imagery & 50 & 1.680 & 1.68 \\
\hline
\end{tabular}


Table 4. ANOVA results for the effect of different textual narrations on participants' use of the submicroscopic level

\begin{tabular}{lcccc}
\hline \multicolumn{1}{c}{ Variance Source } & df & Sum of Squares & Mean Square & F \\
\hline Between Groups & 2 & 66.503 & 33.251 & $16.566^{*}$ \\
\hline Within Groups & 149 & 299.076 & 2.007 & \\
\hline
\end{tabular}

${ }^{*} F$ value is significant at the 0.01 level.

Table 5. Tukey HSD pairwise comparisons for the effect of different textual narrations on participants' use of the submicroscopic level of matter

\begin{tabular}{lcc}
\hline \multicolumn{1}{c}{ Textual Narration Type } & Submicroscopic & Guided Imagery \\
\hline Macroscopic & $1.02^{*}$ & $1.60^{*}$ \\
\hline Submicroscopic & - & 0.58 \\
\hline
\end{tabular}

* The mean difference is significant at the 0.05 level.

Table 6. Examples of participants' explanations at the macroscopic and submicroscopic levels

\begin{tabular}{|c|c|}
\hline Macroscopic Explanations & Submicroscopic Explanations \\
\hline Because of the friction between the two stones, the & These stones are composed of atoms which have electrons. Before the collision, \\
\hline temperature rises up. This produces sparks. ${ }^{\dagger}$ & these electrons are in a stable state. When the two stones collide, atoms become in a \\
\hline $\begin{array}{l}\text { When two stones are hit together, heat is produced } \\
\text { because of the friction. By frequently hitting, the }\end{array}$ & $\begin{array}{l}\text { byper state. There are electrons moving from one orbit to another. } \\
\text { releases energy and a large amount of heat in a form of spark. } \neq\end{array}$ \\
\hline temperature increases and sparks come out. $\ddagger$ & wo stones are hit together, friction takes place between the stones. This \\
\hline When two stones are hit strongly, there is a strong & friction force increases the kinetic energy of the molecules at the surface of the \\
\hline friction force. Applying kinetic energy on the stones, & stones. Then the movement of the electrons at the outer orbits is disturbed. These \\
\hline by bitting them, causes some of this ener & electrons move to far orbits from the nucleus. After this force is gone, these electrons \\
\hline into heat and some to light. When $w$ & return back to their original orbits which causes the release of energy that appears \\
\hline stones, we feel they are hot. We know that the energy & as a spark.t \\
\hline \multirow[t]{2}{*}{ does not disappear, but it changes to other forms. $\ddagger$} & Because of the friction between the two stones, the electrons at the stones' surface \\
\hline & $\begin{array}{l}\text { move from their place and when they return back to their original orbits, they } \\
\text { release photons. These photons are the light. Therefore, sparkes appear. }\end{array}$ \\
\hline
\end{tabular}

† A participant who received the guided imagery version

$\star$ A participant who received the macroscopic version

imagery version outperformed those who received the macroscopic (control) version. There were no significant differences between the submicroscopic version and the guided imagery version.

The textual narrations given to participants dealt with a different phenomenon (the reaction of sodium in water) than what the question required them to explain (the spark formation phenomenon). However, the submicroscopic explanations for both phenomena have some similar considerations. This may explain the significant outscore of both the submicroscopic group and the guided imagery group compared to the macroscopic (control) group. However, participants who received the submicroscopic version and the guided imagery version did not take full advantage of the submicroscopic terminology. According to the submicroscopic level rubric (Table 2), the mean scores for the three groups were low and did not go beyond the Submicro I Level: atoms and molecules. To have a sense of how some participants integrated some submicroscopic terminology, Table 6 illustrates some examples. It might be noted that some participants did not go beyond the macroscopic understanding of the given phenomenon. On the other hand, some participants managed to explain the spark phenomenon using submicroscopic terminology even if they received the macroscopic version.

\section{CONCLUSIONS AND RECOMMENDATIONS}

The purpose of the current study was to examine whether students think at and use the submicroscopic level spontaneously in their explanation of chemical phenomena or whether they need to be cued to do so. For this main purpose, the effect of three different textual versions (macroscopic (control), submicroscopic, and guided imagery) of the explanation of a chemical phenomenon on their submicroscopic explanation of a related phenomenon was tested. The results revealed that thinking at the submicroscopic level has not become a natural habit of chemistry learners in the current study. The out-performance of the 
submicroscopic and guided imagery groups suggests that learners have not yet reached spontaneous submicroscopic thinking. Their brains are not programmed to think at the submicroscopic level unless there is a directing stimulus that cues them to look at the intended phenomenon with a submicroscopic eye. One of the reasons for this phenomenon might be the unbalanced emphasis on the three levels of chemistry by teachers and textbooks. Both macroscopic and symbolic levels dominate the textual and pictorial forms of communication in chemistry practice, while the submicroscopic level does not receive the same weight of emphasis. In some texts it is almost ignored, and the discussion is more mathematical and symbolic in nature. Often, numbers get more attention than atoms and molecules. This type of pedagogic practice produces learners who do not know the chemical principles behind the equations and formulas (Treagust \& Chandrasegaran, 2009).

Another serious epistemological problem revealed by this study is the low submicroscopic level scores achieved by pre-service science teachers. These scores reflect a common problem of the integration of the three levels of chemistry (Correia \& Torres, 2007; Tien, Teichert, \& Rickey, 2007; Treagust \& Chandrasegaran, 2009; Van Berkel, Pilot, \& Bulte, 2009). Students in most science classrooms learn scattered pieces of information and cover different concepts by studying different phenomena. Therefore, they lack the ability to construct a valid explanation that integrates already learned pieces. The low submicroscopic level scores recorded in the current study reveal that students who received the submicroscopic and guided imagery versions could not transfer the knowledge presented in the explanation of the flame phenomenon of the reaction of sodium in water to the sparks formation phenomenon. Science pre-service teachers in the current study had not gained the 'representational competence' by which they consider chemical phenomena in terms of submicroscopic entities to construct meaningful understanding beyond the surface features (Kozma \& Russell, 2005). Most chemistry texts and teachers succeed in explaining the mechanism by which electrons transfer from a lower level of energy to a higher one and then return back, a process that emits energy in photonic form. Different means of media and technology are used to produce sophisticated illustrations that facilitate students' comprehension of this process. However, chemistry textbooks and teachers seldom encourage learners to wonder about different everyday experiences that might be direct applications of the photon emitting phenomenon (Van Berkel et al., 2009). This might be a possible justification for students' failure in using their previous knowledge to wonder about chemical phenomena at the submicroscopic level.
Without designing the environment for such transferred learning, students might never possess the mental ability to use what they have already learned to explore natural phenomena. It might be unlikely that students would build up the competence to translate between the levels of chemistry by themselves (Davidowitz \& Chittleborough, 2009). In order to increase students' submicroscopic thinking, teachers should encourage them to translate macroscopic and symbolic representations into submicroscopic ones. The interactions among atoms and molecules which take place inside the glass beaker to produce changes in colors, temperatures, and textures, should always be visualized sub-microscopically. Using physical 3D models, molecular modeling software programs, and electron density plots are examples of molecular modeling experiences which might be adopted for secondary education and undergraduate chemistry curricula to enhance students' representational competence in chemistry (Kozma \& Russell, 2005). Also, teachers need to learn not to take for granted the idea that students spontaneously switch between the three levels of chemistry. Therefore, they should tackle each phenomenon from three different representational angles: macroscopic, symbolic and submicroscopic (Treagust \& Chandrasegaran, 2009).

The current study explored the effectiveness of providing different textual cues on students' explanation at the submicroscopic level. Further research is needed to explore the effectiveness of other instructional ideas, especially visual cues such as submicroscopic diagrams, dynamic molecular animations, and electron density plots on submicroscopic explanations. Also, comparing textual cues with visual ones will provide insights regarding the best means for stimulating students' spontaneous thinking at the submicroscopic level.

\section{REFERENCES}

Adler, M., \& Flihan, S. (1997). The interdisciplinary continuum: Reconciling theory, research, and practice (Report Series No. 2.36). Albany, NY: Center on English Learning and Achievement.

Al-Balushi, S. M. (2009). Factors Influencing Pre-Service Science Teachers' Imagination at the Microscopic Level in Chemistry. International Journal of Science and Mathematics Education, 7(6), 1089-1110.

Berglung, K. (1997). Look-it's a comet. Science and Children, 35(1), 33-37.

Bucat, B., \& Mocerino, M. (2009). Learning at the sub-micro level: Structural representations. In J. Gilbert \& D. F. Treagust (Eds.), Multiple Representations in Chemical Education, Models and Modeling in Science Education (Vol. 4, pp. 11-30): Springer.

Chandrasegaran, A., Treagust, D. F., \& Mocerino, M. (2009). Emphasizing multiple levels of representation to enhance students' understandings of the change 
occurring during chemical reactions. Journal of Chemical Education, 86(12), 1433-1436.

Cheng, M., \& Gilbert, J. (2009). Towards a better utilization of diagrams in research into the use of representative levels in chemical education. In J. Gilbert \& D. F. Treagust (Eds.), Multiple Representations in Chemical Education, Models and Modeling in Science Education (Vol. 4, pp. 55-73): Springer Science+Business Media.

Correia, P., \& Torres, B. (2007). Using denatured egg white as a macroscopic model for teaching protein structure and introducing protein sysnthesis for high school students. Journal of Chemical Education, 84(12), 1941-1944.

Davidowitz, B., \& Chittleborough, G. (2009). Linking the macroscopic and sub-microscopic levels: Diagrams. In J. Gilbert \& D. F. Treagust (Eds.), Multiple Representation in Chemical Education (Vol. 4, pp. 169-191). Dordrecht, The Netherlands Springer.

Gabel, D. L. (1993). Use of the particulate nature of matter in developing conceptual understanding. Journal of Chemical Education, 70(3), 193-194.

Galyean, B. (1983). Guided imagery in the curriculum. Educational Leadership, 40(6), 54-58.

Galyean, B. (1985). Guided imagery in education. In A. A. Sheikh \& K. S. Sheikh (Eds.), Imagery in Education. Farmingdale, NY: Baywood Publishing Company.

Gilbert, J. (2008). Visualization: An emergent field of practice and enquiry in science education. In J. Gilbert, M. Reiner \& M. Nakhleh (Eds.), Visualization: Theory and Practice in Science Education (pp. pp. 3-24). Dordrecht: Springer.

Halakova, Z., \& Proksa, M. (2007). Two kinds of conceptual problems in chemistry teaching. Journal of Chemical Education, 84(1), 172-174.

Johnstone, A. H. (1993). The development of chemistry teaching. Journal of Chemical Education, 70(9), 701-705.

Kozma, R., \& Russell, J. (2005). Students Becoming Chemists: Developing Representationl Competence. In J. K. Gilbert (Ed.), Visualization in Science Education (pp. 121-146). The Netherlands: Springer.

Myrick, R., \& Myrick, L. (1993). Guided imagery: From mystical to practical. Elementary School Guidance \& Counseling, 28(1), 62-70.

Nakhleh, M. B., \& Samarapungavan, A. (1999). Elementary school children's beliefs about matter. Journal of Research in Science Teaching, 36(7), 777-805.

Tan, K., Goh, N., Chin, C., \& Treagust, D. F. (2009). Linking the macroscopic, sub-microscopic and symbolic levels: The case of inorganic qualitative analysis. In J. Gilbert \& D. F. Treagust (Eds.), Multiple Representations in Chemical Education, Models and Modeling in Science Education (Vol. 4, pp. 137-150): Springer Science+Business Media.

Tien, L., Teichert, M., \& Rickey, D. (2007). Effectiveness of a MORE laboratory module in prompting students to revise their molecular-level ideas about solutions. Journal of Chemical Education, 84(1), 175-181.

Treagust, D. F., \& Chandrasegaran, A. (2009). The efficacy of an alternative instructional programme designed to enhance secondary students' competence in the triplet relationship. In J. Gilbert \& D. F. Treagust (Eds.), Multiple Representations in Chemical Education, Models and Modeling in Science Education (Vol. 4, pp. 151-168): Springer Science+Business Media.
Treagust, D. F., Chittleborough, G. D., \& Mamiala, T. L. (2003). The role of submicroscopic and symbolic representations in chemical explanations. International Journal of Science Education, 25(11), 1353-1368.

Tsaparlis, G. (2009). Learning at the macro level: The role of practical work. In J. Gilbert \& D. F. Treagust (Eds.), Multiple Representations in Chemical Education, Models and Modeling in Science Education (Vol. 4, pp. 109-135): Springer Science+Business Media B.V.

Van Berkel, B., Pilot, A., \& Bulte, M. (2009). Micro-macro thinking in chemical education: Why and how to escape. In D. F. Treagust \& J. Gilbert (Eds.), Multiple Representations in Chemical Education, Models and Modeling in Science Education (Vol. 4, pp. 31-54): Springer Science+Business Media B.V.

Wheatley, W. J., Maddox, E. N., \& Anthony, W. P. (2001). Enhancing guided mental imagery scripts utilized in the classroom. Education, 110(1), 33-39.

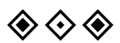

